\title{
Article \\ Effect of Wood Hemicellulose Composition on Binding Interactions with Caffeine
}

\author{
Klára Kobetičová ${ }^{1, *}$ and Jana Nábělková ${ }^{2}$ \\ 1 Department of Materials Engineering and Chemistry, Faculty of Civil Engineering, Czech Technical \\ University in Prague, Thákurova 7, 16629 Prague, Czech Republic \\ 2 Department of Sanitary and Ecological Engineering, Faculty of Civil Engineering, Czech Technical University \\ in Prague, Thákurova 7, 16629 Prague, Czech Republic; nabelkova@fsv.cvut.cz \\ * Correspondence: klara.kobeticova@fsv.cvut.cz
}

Citation: Kobetičová, K.; Nábělková, J. Effect of Wood Hemicellulose Composition on Binding Interactions with Caffeine. Buildings 2021, 11, 515. https://doi.org/10.3390/ buildings 11110515

Academic Editor: Elena Ferretti

Received: 17 September 2021

Accepted: 30 October 2021

Published: 2 November 2021

Publisher's Note: MDPI stays neutral with regard to jurisdictional claims in published maps and institutional affiliations.

Copyright: (c) 2021 by the authors. Licensee MDPI, Basel, Switzerland. This article is an open access article distributed under the terms and conditions of the Creative Commons Attribution (CC BY) license (https:// creativecommons.org/licenses/by/ $4.0 /)$.

\begin{abstract}
Wood is one of the important construction materials and it is necessary to protect it from biological pests. Hemicellulose in wood consist of various sugar hexoses or pentoses depending on the tree species. This composition can have significant effects on interactions with chemical substance as biocides or coatings. Interactions of glucose, arabinose, mannan, galactomannan, glucogalactomannan, xylan, and hemicellulose corresponding its structure in spruce, pine and beech with biocidal substance caffeine was studied in the present study. Chemical analyses were performed spectrometrically at the caffeine optimal wavelength of $287 \mathrm{~nm}$. The results indicate variable rate of interactions between caffeine and the tested sugar monomers or polymers. The largest interactions between caffeine were observed for simple sugars glucose $(71 \%)$ and arabinose $(67 \%)$. Mannan and hemicellulose composted of mannan units had very low interactive potential with caffeine (1-9\%), the models of woody plants showed no statistically significant difference (25-30\%). Nevertheless, hemicellulose in some previous research showed less potential to bind caffeine than lignin, but greater than completely inactive cellulose. It is evident that the structure of individual sugars and their mixture in polymer hemicellulose has effects on binding interactions with caffeine; however, other research in this area will be necessary in the future.
\end{abstract}

Keywords: caffeine; hemicellulose; wood; polysaccharides

\section{Introduction}

Wood is amongst the oldest and the most used building materials in human history. It can be used for indoor and outdoor applications as columns, beams or trusses, wooden cladding and facades, interior elements, bridges or footbridges. Wood has excellent properties as a construction material. In addition, wood is a renewable source and is easily recyclable. Different types of woody plants, both of domestic origin and exotic woods, are suitable for different construction uses. The wood species used most in Europe are spruce, beech, oak and pine, and larch [1,2]. While spruce is the most commonly used material for outdoor use, beech wood is very suitable for interiors, which is also used in the food industry (popsicle sticks), medicine (spatulas), for the production of toys, beads, veneers, small objects and other wood-based materials [2].

Generally speaking, wood consists of lignin (25-35\%), cellulose (32-56\%), hemicelluloses (15-45\%), pectins, various additional chemicals (1-30\%), whose composition affects the physical-chemical properties of wood [3]. Cellulose and hemicellulose create the main building component of plant primary cell walls and secondary cell walls [4]. Hemicelluloses are composed of various pentoses (arabinose, xylose) and hexoses (glucose, mannose, galactose). These linear polysaccharides have short side chains and a smaller degree of crystals than cellulose [3]. However, the chemical structure of woody plants varies from wood kind to kind and also depends on the location, age and condition of individual trees [5]. Such differences can lead to diverse interactions of woody plants with various 
chemicals such as mordants, paints, varnishes and pest control. Mainly biodegradation or eutrophication of woods used for construction purposes is a very significant problem, which also applies to other building materials [6].

One of the most explored substance against biological pests is caffeine in recent years (Figure 1). This methylxanthine is of natural origin and its suitable applicability has been verified many times. However, its success against biological pests varies among the individual pests-termites, fungi, moulds [7-15]. This, of course, is related both to the sensitivity of individual organisms to this substance, individual test performance, and to the composition of the woody plants that are treated with caffeine-containing preparations.

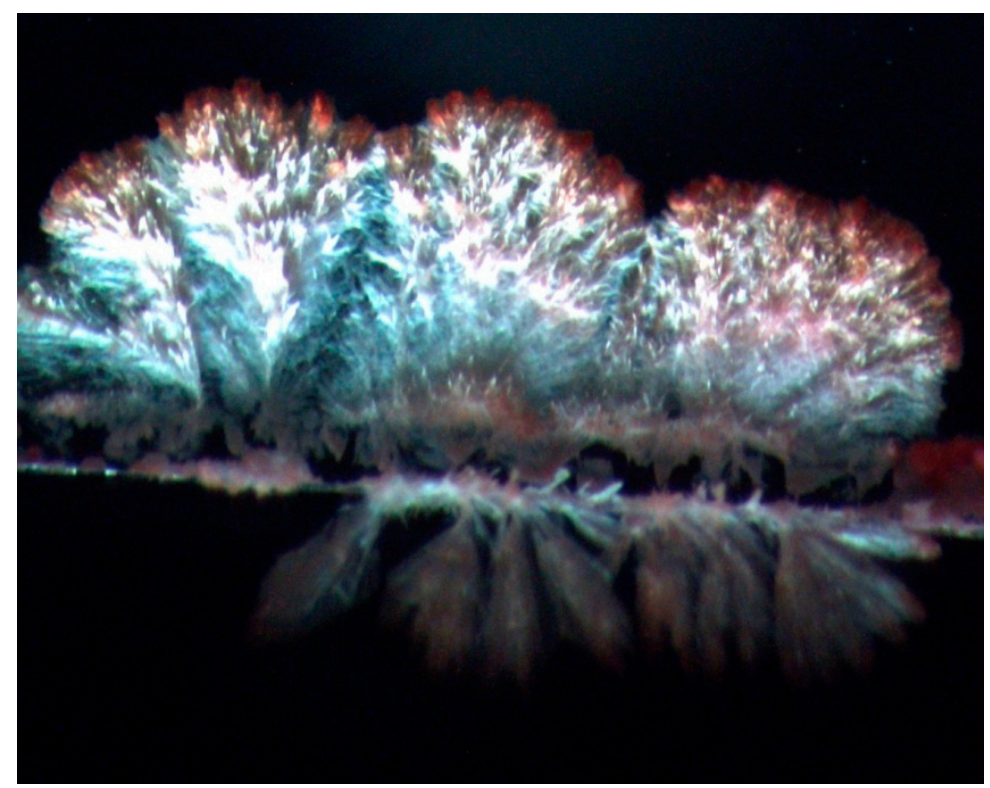

Figure 1. Caffeine crystals coloured by safranin under the transmitted light of a microscope (40x magnification).

In the newest studies, the significant effects of lignin and its alcohol precursors on binding interactions of wood were described. Whereas cellulose did not interact with the caffeine molecules in both prior studies, the opposite was the case for hemicellulose and its alcohol precursors [16].

However, the study of the interactions of caffeine with hemicellulose has not yet received attention instead of one study [16]. In this study, the interactions of hemicellulose with caffeine were confirmed to be lower than for lignin, yet greater than for cellulose, which was inactive. Hemicellulose forms the filler between cellulose and lignin, and it is quite possible that if the binding of caffeine to this wood component together with the binding to lignin can have an important effect on the resistance of wood to pests and even on the durability of coating systems in general.

In general, the interaction of chemicals with wood can be based on physical or chemical interactions. These basic bonds include intermolecular bonds (hydrogen bridges, Van der Walls forces, metal binding, stacking), or chemical covalent, donor-acceptor or ionic bonds. However, we do not know much about the type of these relationships between caffeine and hemicellulose.

For these reasons, hemicellulose and its binding interactions with caffeine is a main goal of the actual study. This approach is new and can bring interesting knowledge and stimuli for further research into the issue of binding interactions of caffeine or the other similar biologically active substances with basic wood components. The interactions of caffeine and various pentoses (arabinose, xylose), hexoses (glucose, galactose, mannose, galactomannose) occurring in wood and their mixtures in such proportions as they occur in spruce (mannan:xylan $=5: 3)$, pine $($ mannan:xylan $=1: 1)$ and beech $($ mannan:xylan $=1: 19)$ and in the generally described hemicellulose model (D-mannose + D-glucose + D-galactose 
in ratio $=3: 1: 1)$ were studied. Our results are discussed with available literature sources and caffeine interactions with hemicellulose and its individual sugar precursors are described.

\section{Materials and Methods}

\subsection{Chemicals}

Caffeine, mannan (consist of D-mannose, D-glucose and D-galactose in ration 3:1:1) and glucose were purchased from Sigma-Aldrich, Ltd. (Prague, Czech Republic). Xylan, galactomannan, arabinose were purchased from P-Lab, Ltd. (Prague, Czech Republic). All of the substances were in powder the form (>99\% purity). The glucogalactomann was prepared in a ratio: $\mathrm{D}$-mannose $+\mathrm{D}$-glucose $+\mathrm{D}$-galactose in ratio $=3: 1: 1$. Deionized water was used as a solvent for the preparation of aquatic solutions or suspensions.

\subsection{Experiment Procedure}

Water stock solution of caffeine $(1 \mathrm{~g} / \mathrm{L})$ was used. The caffeine concentration was selected according to results from the previous study [16]. $30 \mathrm{~mL}$ glass bottles were fulfilled by $20 \mathrm{~mL}$ of caffeine solution with $20 \mathrm{mg}$ of the appropriate sugar or biopolymer in powder form. The controls for analytical measurements were pure caffeine solution $(1 \mathrm{~g} / \mathrm{L})$ and pure precursor or their mixtures $(1 \mathrm{~g} / \mathrm{L})$. The caffeine and hemicellulose components were mixed before exposition in an incubator. The bottles were stored in an incubator at a temperature of $20 \pm 2{ }^{\circ} \mathrm{C}$ in the dark. The analyses were made after $72 \mathrm{~h}$ of exposure. Triplicates were prepared for pure caffeine solution, all pure sugar mixtures and the mixtures of caffeine with sugar mixtures.

\subsection{Chemical Analyses}

Spectrophotometer Biochrom Libra S22 was used for determination of all solutions $(5 \mathrm{~mL})$. The optimal wavelength of caffeine $=287 \mathrm{~nm}$ was used [16]. The pure sugar or sugar-polymers absorbance values were the controls for subtracting the amount of caffeine in solutions containing caffeine and a certain sugar or polysaccharide mixture thereof.

\subsection{Statistical Analyses}

The absorbance in the presence/absence of caffeine in solutions of the individual sugars or their mixtures were used to calculate caffeine concentrations in all of the samples. The caffeine absorbance in the mixtures (except for the caffeine absorbance in the pure caffeine solution) were calculated according to Formula (1):

$$
(A-C F)=x b-x a,
$$

where $(\mathrm{A}-\mathrm{CF})$ is the absorbance of caffeine in the caffeine solution mixture with any sugar or their mixture, $\mathrm{xb}$ is the absorbance of caffeine-sugar/mixture and $\mathrm{xa}$ is the absorbance of the same pure sugar/mixture [16].

The percentage ration $(\mathrm{R})$ of caffeine bonding to sugar monomers or their mixtures was calculated according to Formula (2):

$$
(\mathrm{R})=\mathrm{A}(\mathrm{SP} \text { or } \mathrm{M}) / \mathrm{A}(\mathrm{CF}) * 100 \text {, }
$$

where $(\mathrm{R})$ is a percentage ration $(\mathrm{R})$ of caffeine bonding to hemicellulose components (in $\%), \mathrm{A}(\mathrm{SP})$ is an absorbance of caffeine-sugar component complex, $\mathrm{A}(\mathrm{M})$ is an absorbance of caffeine-sugar mixture components complex, $\mathrm{A}(\mathrm{CF})$ is is an absorbance of pure caffeine [16].

The absorbance values (for all three replicates of caffeine + the sugar(s) minus the sugar(s)) were compared to the using multivariate nonparametric ANOVA, Kruskal-Wallis Test (GrapPad InStat, version 3.06; GraphPad Software Inc., San Diego, CA, USA, 2003).

\section{Results}

The measured absorbance values are relatively consistent (Table 1) with very low standard deviations (0.001-0.013). The residual caffeine (CF) concentration in the solution of 
glucose or arabinose showed a statistically significant difference compared to the pure caffeine solution hemicellulose (GGM) versus glucose. On the other hand, other combinations were not statistically significant (Table 2). The substance with the highest affinity to caffeine was glucose, followed by arabinose, then polysaccharide xylan followed by polysaccharide mixtures imitating hemicellulose in pine, spruce and beech. The least interactions were observed for glucomannan, general glucogalactomannan and mannan (Figure 2).

Table 1. Absorbance of tested samples at $\lambda=287 \mathrm{~nm}$ : caffeine (CF), hemicellulose (HC), galactomannan (GM: D-mannose + D-glucose + D-galactose in ratio = 3:1:1), mannan $(\mathrm{M})$, galactan $(\mathrm{GT})$, glucose $(\mathrm{G})$, arabinose $(\mathrm{A})$, xylan $(\mathrm{X})$, spruce $($ mannan: xylan ratio $=5: 3$ ), pine (mannan: xylan ratio $=1: 1$ ) and beech (mannan: xylan ratio $=1: 19$ ). Primary data $(n=3)$, mean values of absorbance $[\mathrm{A}]$ and their standard deviations (SD).

\begin{tabular}{|c|c|c|c|c|c|c|c|c|}
\hline & Substance & $\begin{array}{l}1 . \\
{[A]}\end{array}$ & $\begin{array}{l}2 . \\
{[A]}\end{array}$ & $\begin{array}{l}3 . \\
{[A]}\end{array}$ & $\begin{array}{l}\text { Average } \\
\text { [A] }\end{array}$ & $\begin{array}{l}\text { SD } \\
{[A]}\end{array}$ & $\begin{array}{c}\text { A-CF: } \\
\text { (IIb-IIa to VIIb-VIIa) [A] }\end{array}$ & $\begin{array}{c}\text { Average } \\
\mathrm{CF}-(\mathrm{A}-\mathrm{CF}) \\
{[\mathrm{A}]}\end{array}$ \\
\hline I & $\mathrm{CF}$ & 0.737 & 0.748 & 0.749 & 0.745 & 0.007 & 0.745 & - \\
\hline IIa & $\mathrm{HC}$ & 0.028 & 0.025 & 0.022 & 0.025 & 0.003 & & \\
\hline $\mathrm{IIlb}$ & $\mathrm{CF}+\mathrm{HC}$ & 0.725 & 0.732 & 0.738 & 0.732 & 0.007 & 0.707 & 0.038 \\
\hline IIIa & GM & 0.059 & 0.059 & 0.050 & 0.055 & 0.005 & & \\
\hline $\mathrm{IIIb}$ & $\mathrm{CF}+\mathrm{GM}$ & 0.729 & 0.741 & 0.738 & 0.736 & 0.006 & 0.681 & 0.065 \\
\hline IVa & M & 0 & 0 & 0 & 0 & 0 & & \\
\hline $\mathrm{IVb}$ & $\mathrm{CF}+\mathrm{M}$ & 0.736 & 0.743 & 0.735 & 0.738 & 0.004 & 0.738 & 0.007 \\
\hline $\mathrm{Va}$ & G & 0.020 & 0.019 & 0.020 & 0.020 & 0.001 & & \\
\hline $\mathrm{Vb}$ & $\mathrm{CF}+\mathrm{G}$ & 0.236 & 0.236 & 0.235 & 0.235 & 0.001 & 0.215 & 0.529 \\
\hline VIa & A & 0.051 & 0.054 & 0.054 & 0.053 & 0.002 & & \\
\hline $\mathrm{VIb}$ & $\mathrm{CF}+\mathrm{A}$ & 0.300 & 0.303 & 0.304 & 0.302 & 0.002 & 0.249 & 0.495 \\
\hline VIIa & $x$ & 0.455 & 0.460 & 0.464 & 0.460 & 0.005 & & \\
\hline VIIb & $\mathrm{CF}+\mathrm{X}$ & 0.928 & 0.923 & 0.937 & 0.929 & 0.007 & 0.469 & 0.275 \\
\hline VIIIa & spruce & 0.265 & 0.268 & 0.261 & 0.265 & 0.003 & & \\
\hline VIIIb & $\begin{array}{c}\mathrm{CF}+ \\
\text { spruce }\end{array}$ & 0.805 & 0.815 & 0.805 & 0.810 & 0.006 & 0.545 & 0.199 \\
\hline IXa & pine & 0.363 & 0.360 & 0.364 & 0.362 & 0.002 & & \\
\hline $\mathrm{IXb}$ & $\mathrm{CF}+$ pine & 0.869 & 0.889 & 0.894 & 0.884 & 0.013 & 0.522 & 0.223 \\
\hline $\mathrm{Xa}$ & beech & 0.276 & 0.277 & 0.281 & 0.278 & 0.003 & & \\
\hline $\mathrm{Xb}$ & CF + beech & 0.842 & 0.833 & 0.837 & 0.837 & 0.005 & 0.559 & 0.185 \\
\hline
\end{tabular}

\section{Discussion}

Caffeine in aquatic solution was the focus of attention in this study. It has been shown that caffeine in aqueous solution preferentially forms hydrogen bonds with water molecules and that the caffeine-sugar bond occurs by a different mechanism. Some researchers investigated that sugars weakly bind to caffeine by face-to-face stacking, similar to the binding of caffeine molecules to each other. This mode of interaction does not affect the hydrogen bonding of the sugar molecules to water [17-20].

Hemicelluloses are usually composed of various monomers-hexoses and pentoses. The composition of hemicellulose is variable among individual tree species [21]. Compared to cellulose, which has only a chain of glucose units, the hemicellulose chain is irregular and therefore cannot be precisely structurally defined and plotted. Compared to cellulose, hemicelluloses are more soluble in water and better degrade into simple sugars. The smaller sugar units of hemicellulose or individual pentose or hexose can probably bond better to caffeine than cellulose and partly better than lignin [16,22]. Hemicellulose composition is therefore very important for the success of binding interactions.

It is evident that the ratios of interactions with caffeine decreased with the complexity of tested polysaccharide mixtures. Such results are not very surprising because glucose and arabinose are small molecules in contrast to the rest of tested, more complex polymers. Such small and simple molecules (Figure 3) might easier and faster react with simple molecules of caffeine. It was verified that even the sucrose, glucose or sorbitol are bound to caffeine by the interaction of the aliphatic hydrophobic protons of the sugar with the 
caffeine face. This intermolecular association via face-to-face stacking were suggested by simulation and various experimental studies. While the interactions of glucose in aquatic solutions have been well described in the latest studies [17-20], Interactions of caffeine with arabinose have not been studied yet. Nevertheless, these simple interactions are only illustrative in the present study, because hemicellulose is composed of many sugar units in the woods. Nevertheless, we can suppose the same bonding interactions of arabinose to caffeine as in the case of glucose because it showed an even stronger binding interaction more than arabinose in the present study.

Table 2. The comparison of absorbance values for all three replicates of "caffeine + the individual sugar(s)" minus "the same sugar(s)" were compared using multivariate nonparametric ANOVA, Kruskal-Wallis Test (significance: n.s. = not significant; ${ }^{*}=$ low significance corresponding to difference $21.000 ;{ }^{* *}=$ higher significance corresponding to difference 24.000).

\begin{tabular}{|c|c|c|c|}
\hline Comparison & Difference & Significance & $p$ Value \\
\hline CF vs. GGM & 3.000 & n.s. & $>0.05$ \\
\hline CF vs. GM & 6.000 & n.s. & $>0.05$ \\
\hline CF vs. G & 24.000 & $* *$ & $<0.01$ \\
\hline CF vs. A & 21.000 & * & $<0.05$ \\
\hline CF vs. $X$ & 18.000 & n.s. & $>0.05$ \\
\hline CF vs. spruce & 12.000 & n.s. & $<0.05$ \\
\hline CF vs. pine & 15.000 & n.s. & $>0.05$ \\
\hline CF vs. beech & 9.000 & n.s. & $>0.05$ \\
\hline GGM vs. GM & 3.000 & n.s. & $>0.05$ \\
\hline GGM vs. G & 21.000 & * & $>0.05$ \\
\hline GGM vs. A & 18.000 & n.s. & $>0.05$ \\
\hline GGM vs. $X$ & 15.000 & n.s. & $>0.05$ \\
\hline GGM vs. spruce & 9.000 & n.s. & $<0.05$ \\
\hline GGM vs. pine & 12.000 & n.s. & $>0.05$ \\
\hline GGM vs. beech & 6.000 & n.s. & $>0.05$ \\
\hline GM vs. G & 18.000 & n.s. & $>0.05$ \\
\hline GM vs. A & 15.000 & n.s. & $>0.05$ \\
\hline GM vs. $X$ & 12.000 & n.s. & $>0.05$ \\
\hline GM vs. spruce & 6.000 & n.s. & $>0.05$ \\
\hline GM vs. pine & 9.000 & n.s. & $>0.05$ \\
\hline GM vs. beech & 3.000 & n.s. & $>0.05$ \\
\hline G vs. A & -3.000 & n.s. & $>0.05$ \\
\hline G vs. X & -6.000 & n.s. & $>0.05$ \\
\hline G vs. spruce & -12.000 & n.s. & $>0.05$ \\
\hline G vs. pine & -9.000 & n.s. & $>0.05$ \\
\hline G vs. beech & -15.000 & n.s. & $>0.05$ \\
\hline A vs. $X$ & -3.000 & n.s. & $>0.05$ \\
\hline A vs. spruce & -9.000 & n.s. & $>0.05$ \\
\hline A vs. pine & -6.000 & n.s. & $>0.05$ \\
\hline A vs. beech & -12.000 & n.s. & $>0.05$ \\
\hline X vs. spruce & -6.000 & n.s. & $>0.05$ \\
\hline$X$ vs. pine & -3.000 & n.s. & $>0.05$ \\
\hline X vs. beech & -9.000 & n.s. & $>0.05$ \\
\hline spruce vs. pine & 3.000 & n.s. & $>0.05$ \\
\hline spruce vs. beech & -3.000 & n.s. & $>0.05$ \\
\hline pine vs. beech & -6.000 & n.s. & $>0.05$ \\
\hline
\end{tabular}

The other studied chemicals are more complex polymers. Xylan, for which a certain level of binding interactions was proven, consisted of pentose sugars. Typically, xylans amount in hardwoods (beech in the present study) is $10-35 \%$, whereas it is $10-15 \%$ in softwoods (pine, spruce in the present study). Xylan is the most interactive polymer of those tested, it shows the highest binding interactions (see Figure 2). It is quite probable that this is influenced by the presence of pentose sugar units instead of hexoses, because xylan is formed mainly by the arabinose units (Figure 4). 
Generally, mannan and its incorporation into the polymer lead to low interactions with caffeine molecules. When we compare data for commercially prepared mannan, glucomannan and glucogalactomannan prepared by us in the laboratory, the galactose units in the mixture appear to lead to a reduction in binding in this case. Models describing the spatial interactions of caffeine with carbohydrates have so far been designed only for simple sugars such as glucose or fructose $[17,20]$. In the case of polymeric structures such as inhomogeneous hemicellulose, this is impossible for the time being.

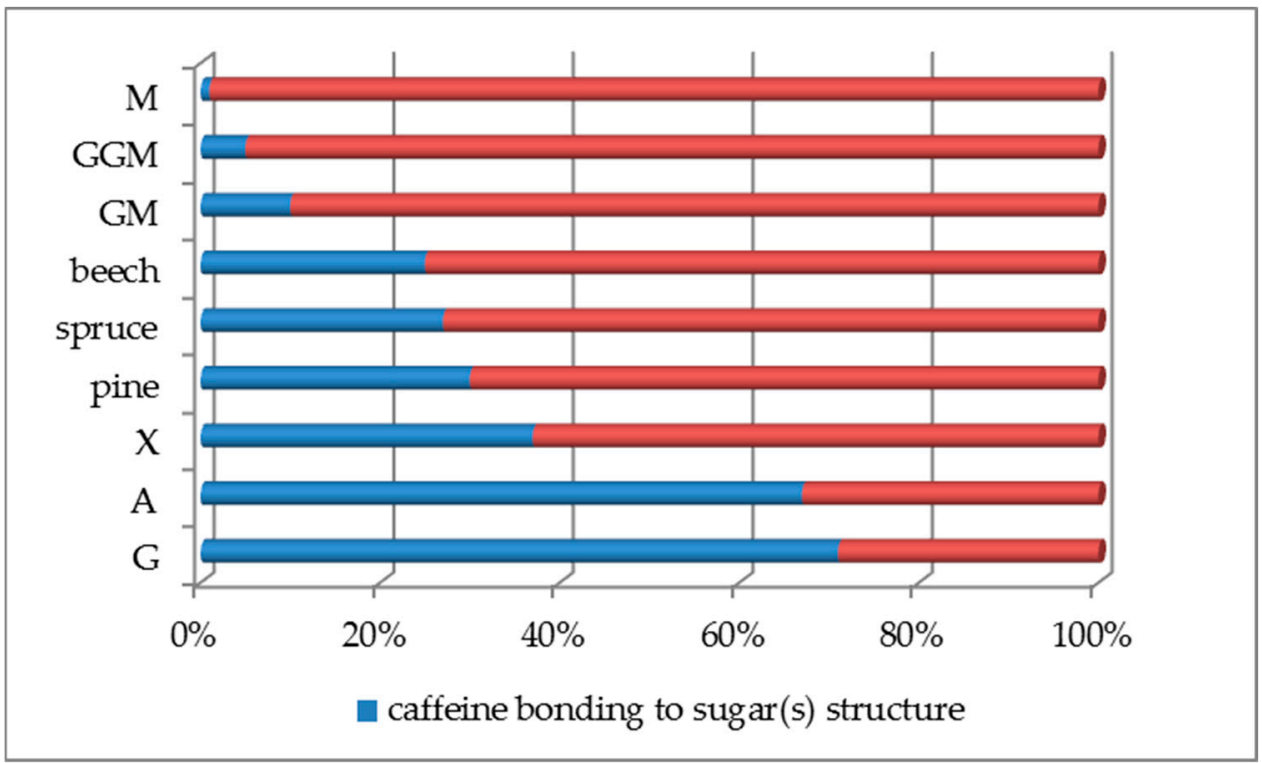

Figure 2. Levels of caffeine (in \% of $1 \mathrm{~g} / \mathrm{L}$ ) bonding to hemicellulose (glucogalactomannan-GGM), its sugar precursors (glucose $=\mathrm{G}$, arabinose $=\mathrm{A}$ ) and the sugar polymers (xylan = X, mannan = M, galactomannan $=\mathrm{GM}$ ) and the polysaccharides ratio corresponding to hemicelluloses of spruce, pine or beech wood.<smiles></smiles><smiles>OC1OC(O)C(O)C(O)C1O</smiles><smiles>CC1C2OC3OC(C3O)C1O2</smiles>

Figure 3. Chemical structure of caffeine, glucose and arabinose (from left to right).<smiles>COC1OC2COC(OC)C(OC(C)=O)C(O2)C1O</smiles>

Figure 4. Chemical structure of xylan.

The statistical analysis confirmed the significant difference just between the relations of GGM-glucose (see Table 2). Generally, it seems that these reduced hemicellulose-caffeine interactions are affected by lower amount of place for binding interactions on sugar polymers. One study described that the binding in caffeine in sugar complexes is bonding through the hydrophobic sites in rings and hydrogen interactions are not expected [17] as at monomer sugars. 
One can suppose that this assumption also applies to the other sugars or hemicelluloses. Interactions of caffeine with certain drugs and additives $[18,19]$ are very well described, the research of interactions between wood and paint containing caffeine have only just begun. Similar studies to the present study have not been performed, and for this reason, is not possible to compare our data with any previous values.

Model trees "pine", "spruce" and "beech" consist of various mannan and xylan ratios: spruce (mannan:xylan $=5: 3)$, pine $($ mannan:xylan $=1: 1)$ and beech $($ mannan:xylan $=1: 19)$. Although their interaction with caffeine is very similar and statistically insignificant, the beech that contains the most xylan is controversially to the earlier text relatively the least reactive. In contrast, pine, which contains the same amount of both polysaccharides, has the best results. It therefore appears that the binding of caffeine is influenced by the disproportion of the two carbohydrates in the mixture and the number of free carbonyl and oxo groups of xylan.

When caffeine was used as an active biocidal substance in any mixture (mainly soluble in water, pure or with metal nanoparticles, or with propolis), the coating was applied to beech, spruce or pine $[8-10,13]$. Caffeine application leads to variable protective efficiency against selected pests [7-15]. Our data from the present study indicate that application of caffeine on the covers of these most commonly used woods might be affected by composition of hemicellulose together with lignin presence [16].

It is generally known that wood-destroying fungi (not molds) are divided into fungi that cause white or brown rot of wood according to which part of the wood mass they degrade (whether only cellulose and hemicelluloses or also lignin). The relationship between the species or group of wood pests (insects, molds, fungi) and their specific food preference (individual sugars or polysaccharides), however, have also never been studied in detail.

\section{Conclusions}

Interactions of monosaccharide glucose and arabinose or polysaccharide mannan, galactomannan, glucogalactomannan, xylan, and hemicellulose corresponding to its structure to spruce, pine and beech with biocidal substance caffeine was studied in the present study. The measured data indicate that the most significant interactions with caffeine were in simple sugars such as glucose and arabinose, followed by xylan, whilst a lower rate of interactions was ascertained in the other hemicellulose models.

No difference was found in the efficiency of caffeine binding to hemicellulose of woody plants such as beech, pine and spruce. Based on these results, it appears that hemicellulose, as demonstrated for cellulose in the previous study [22], does not have a significant binding effect of caffeine to wood for these most commonly used wood species in building structures. The main component of wood in this respect is lignin [16,22], or some other, hitherto unexplored accompanying substances of woody plants from this point of view.

Author Contributions: Conceptualization, K.K.; methodology, K.K.; software, K.K.; validation, K.K. and J.N.; formal analysis, K.K.; investigation, K.K.; resources, K.K.; data curation, K.K.; writingoriginal draft preparation, K.K. and J.N.; writing-review and editing, K.K. and J.N.; visualization, K.K. and J.N.; supervision, K.K.; project administration, K.K.; funding acquisition, K.K. All authors have read and agreed to the published version of the manuscript.

Funding: This research was funded by the Czech Science Foundation, grant number 19-02067S.

Institutional Review Board Statement: Not applicable.

Informed Consent Statement: Not applicable.

Data Availability Statement: All data are a part of manuscript. 
Acknowledgments: This research has been supported by the Czech Science Foundation under the Project No. 19-02067S.

Conflicts of Interest: The authors declare no conflict of interest.

\section{References}

1. Panshin, A.J.; de Zeeuw, D. Textbook of Wood Technology, 4th ed.; McGraw-Hill: New York, NY, USA, 1980.

2. Svatoň, J. Ochrana Dřeva, 1st ed.; Mendel University in Brno: Brno, Czech Republic, 2000.

3. Carpita, N.C.; Giheaut, D.M. Structural models of primary cell walls in flowering plants: Consistency of molecular structure with the physical properties of the wall during growth. Plant J. 1993, 3, 1-30. [CrossRef] [PubMed]

4. Gibsen, L.J. The hierarchical structure and mechanics of plant materials. J. R. Soc. Interface 2012, 9, 2749-2766. [CrossRef] [PubMed]

5. Rowell, R.M. Handbook of Wood Chemistry and Wood Composites; CRC Press: Boca Raton, FL, USA, 2005.

6. Kobetičová, K.; Černý, R. Terrestrial eutrophication of building materials and buildings: An emerging topic in environmental studies. Sci. Total Environ. 2019, 686, 1316-1328. [CrossRef] [PubMed]

7. Arora, D.S.; Ohlan, D. In vitro studies on antifungal activity of tea (Camellia sinensis) and coffee (Coffea arabica) against wood-rotting fungi. J. Basic Microbiol. 1997, 37, 159-165. [CrossRef]

8. Ratajczak, I.; Wozniak, M.; Kwasniewska-Sip, P.; Szentner, K.; Cofta, G.; Mazela, B. Chemical characterization of wood treated with a formulation based on propolis, caffeine and organosilanes. Eur. J. Wood Wood Prod. 2018, 76, 775-781. [CrossRef]

9. Kwasniewska-Sip, P.; Cofta, G.; Nowak, P.B. Resistance of fungal growth on Scots pine treated with caffeine. Int. Biodeterior. Biodegrad. 2018, 132, 178-184. [CrossRef]

10. Kwasniewska-Sip, P.; Bartkowiak, M.; Cofta, G.; Nowak, P.B. Resistance of Scots Pine (Pinus sylvestris L.) after Treatment with Caffeine and Thermal Modification against Aspergillus niger. Bioresources 2019, 14, 1890-1898.

11. Kobetičová, K.; Böhm, M.; Černý, R. Mutual interactions of fungi and molds on woods treated with a caffeine solution: A preliminary study. AIP Conf. Proc. 2020, 2275, 020010.

12. Kobetičová, K.; Nábělková, J.; Ďurišová, K.; Šimůnková, K.; Černý, R. Antifungal Activity of Methylxanthines in Relation to their Properties. Bioresources 2020, 15, 8110-8120. [CrossRef]

13. Pánek, M.; Šimůnková, K.; Novák, D.; Dvořák, O.; Schönfelder, O.; Šedivka, P.; Kobetičová, K. Caffeine and TiO 2 Nanoparticles Treatment of Spruce and Beech Wood for Increasing Transparent Coating Resistance against UV-Radiation and Mould Attacks. Coatings 2020, 10, 1141. [CrossRef]

14. Zhang, H.; Qi, L.; Zhang, Z. Antifungal activity of caffeine against fungal pathogens of tea plant. J. Nanjing. Agric. Univ. 2020, 2, 63-67.

15. Šimůnková, K.; Reinprecht, L.; Nábělková, J.; Hýsek, Š.; Kindl, J.; Borůvka, V.; Lišková, T.; Šobotník, J.; Pánek, M. CaffeinePerspective natural biocide for wood protection against decaying fungi and termites. J. Clean. Prod. 2021, 304, 127110. [CrossRef]

16. Kobetičová, K.; Ďurišová, K.; Nábělková, J. Caffeine Interactions with Wood Polymers. Forests 2021, 12, 533. [CrossRef]

17. Tavagnacco, L.; Engström, O.; Schnupf, U.; Saboungi, M.-L.; Himmel, M.; Widmalm, G.; Cesàro, A.; Brady, J.W. Caffeine and Sugars Interact in Aqueous Solutions: A Simulation and NMR Study. J. Phys. Chem. B 2020, 116, 11701-11711. [CrossRef] [PubMed]

18. Albertini, B.; Melegari, C.; Bertoni, S.; Dolci, L.S.; Passerini, N. A Novel Approach for Dry Powder Coating of Pellets with Ethylcellulose. Part II: Evaluation of Caffeine Release. AAPS Pharm. Sci. Tech. 2018, 19, 1426-1436. [CrossRef] [PubMed]

19. Bushra, R.; Aslam, N.; Khan, A.Y. Food-Drug Interactions. Oman Med. J. 2011, 26, 77-83. [CrossRef] [PubMed]

20. Tavagnacco, L.; Brady, J.W.; Cesáro, A. The Interaction of Sorbitol with Caffeine in Aqueous Solution. Food Biophys. 2013, 8, 216-222. [CrossRef] [PubMed]

21. Blažej, A.; team of authors. Tenzidy, 1st ed.; Alfa, SNTL: Prague, Czech Republic, 1977.

22. Kwasniewska-Sip, P.; Wozniak, M.; Jankowski, W.; Ratajczak, I.; Cofta, G. Chemical Changes of Wood Treated with Caffeine. Materials 2021, 14, 497. [CrossRef] [PubMed] 